\title{
A fading procedure facilitates the maintenance of observing responses when the more valued stimulus is not produced
}

\author{
BARBARA J. KAMINSKI and JAY MOORE \\ University of Wisconsin, Milwaukee, Wisconsin
}

\begin{abstract}
Pigeons served in two experiments in which responding on an observing key converted a twocomponent mixed schedule to the corresponding multiple schedule of reinforcement. Presentation of the stimulus correlated with the more valued component was faded out (probabilistically) over sessions, so that ultimately an observing response produced only the stimulus correlated with the less valued component. Observing was well maintained after a fading procedure when a stimulus was produced by a single response, regardless of whether the less valued stimulus was associated with food or with extinction (Experiment 1). However, observing was not well maintained after a fading procedure when a stimulus was produced according to an intermittent schedule (Experiment 2). Taken together, the results of the two experiments suggest that the absence of an exteroceptive stimulus change after a single response may become discriminative in its own right for the more valued component, and that the fading procedure is an effective means of promoting this discrimination. However, if observing responses produce a stimulus change according to an intermittent schedule, then the absence of a stimulus change after a response is correlated with both components. Under these conditions, the absence of stimulus change is not discriminative for either component, even with fading, and observing is not maintained.
\end{abstract}

In an observing response procedure, a designated response produces a stimulus correlated with the prevailing component of a compound schedule of reinforcement. The response does not change the prevailing component or increase the probability of reinforcement in its presence in any way. Most research on observing has been concerned with assessing the stimulus-reinforcer relations that contribute to the maintenance of observing. The results of this research generally suggest that observing is maintained only by the production of the stimulus correlated with the more valued schedule, and not by the production of the stimulus correlated with the less valued schedule. "More valued" is defined here in terms of one or another parameter of reinforcement, such as higher rate or larger amount, provided by the schedule with which the stimulus in question is correlated (Branch, 1970; Browne \& Dinsmoor, 1974; Dinsmoor, Browne, \& Lawrence, 1972; Fantino \& Case, 1983; Jwaideh \& Mulvaney, 1976; Katz, 1976; Kendall \& Gibson, 1965; Killeen, Wald, \& Cheney, 1980; Mulvaney, Dinsmoor, Jwaideh, \& Hughes, 1974; Mulvaney, Hughes, Jwaideh, \& Dinsmoor, 1981; Wald

\footnotetext{
Experiment 1 was carried out as a Senior Honors Thesis by Barbara $\mathbf{J}$. Kaminski under the supervision of Jay Moore. The data were presented at the convention of the American Psychological Association in Atlanta, August 1988. The authors thank Stephen Kendall, James Dinsmoor, and Michael Perone for helpful comments on earlier versions of the paper, and Joe Jones for his expert assistance with Experiment 2. Please address all correspondence and requests for reprints to Jay Moore, Department of Psychology, University of Wisconsin, P.O. Box 413, Milwaukee, WI 53201
}

\& Dukich, 1978). In this regard, Fantino's (1977) delay reduction account has been shown to make accurate quantitative predictions regarding the maintenance of observing by a stimulus correlated with the more valued of the two schedules.

Nevertheless, some data do suggest that a less valued stimulus will maintain observing, and that a less valued stimulus may therefore qualify to be considered as a reinforcer for observing (Lieberman, 1972; Perone \& Baron, 1980; Schaub, 1969; Schaub \& Honig, 1967; Schrier, Thompson, \& Spector, 1980). If these data are generally valid, they would constitute a limitation on extant theories of reinforcement and observing. However, both Fantino (1977) and Dinsmoor (1983) have suggested that there are alternative interpretations of these data. For example, Fantino (1977) has argued that Lieberman's (1972) results may be interpreted as a special case of response competition that does not necessarily demonstrate that the less valued stimulus is a reinforcer for observing. Dinsmoor (1983, p. 719) has suggested that Perone and Baron's (1980) results may be explained in terms of the escape from an aversive task, rather than in terms of the conditioned reinforcing effectiveness of the less valued stimulus.

Both Dinsmoor et al. (1972; see also Dinsmoor, 1983) and Fantino (1977) have suggested that an alternative interpretation of the remaining studies is also possible. Those studies involved a procedure in which responding on an observing manipulandum produced stimulus changes according to relatively short and fixed response requirements (usually fixed-ratio [FR]1 to FR5). The usual outcome is that observing is not maintained when the less 
valued, rather than the more valued, of the two stimuli is the only stimulus produced, even with short FR observing response requirements (Dinsmoor, Flint, Smith, \& Viemeister, 1969; Fantino \& Case, 1983; Katz, 1976; Kendall \& Gibson, 1965; Killeen et al., 1980; Wald \& Dukich, 1978). However, Dinsmoor (1983) and Fantino (1977) have pointed out that observing might be maintained, and that the less valued stimulus might appear to be reinforcing, if the absence of any exteroceptive stimulus change after a response becomes discriminative for the presence of the more valued schedule, which might be the case when stimulus changes are produced according to short FR observing requirements.

Interestingly, Kendall (1974) has reported data that bear directly on this problem. In the first portion of his study, pigeons were trained in an observing response procedure in which the more valued stimulus was correlated with an FR35 schedule and the less valued stimulus with an FI (fixed-interval) 2-min schedule. Only a single peck (i.e., the observing schedule was FR1) was necessary to produce a stimulus correlated with the prevailing schedule. When an observing response produced either stimulus, the pigeons responded readily on the observing key. However, when Kendall abruptly changed experimental conditions, such that a response produced only the less valued stimulus, the pigeons virtually ceased to observe.

In the second portion of the experiment, Kendall (1974) reinstated the more valued stimulus, recovered the baseline performance, and then gradually reduced (over sessions) the probability that an observing response would produce the more valued stimulus. The term "fading" will be used here to describe this manipulation. Thus, over successive sessions, the more valued stimulus was produced on fewer and fewer occasions, until eventually it was not produced at all during a session. The less valued stimulus remained available in the standard way as a consequence of the observing response.

Using this probabilistic fading procedure, Kendall (1974) found that observing was maintained, at least to some degree, when the more valued stimulus was not produced. He considered the possibility that the less valued stimulus had somehow become reinforcing, but he rejected it. He hypothesized instead that the fading procedure gave the animal an opportunity to learn that when a response did not produce an exteroceptive stimulus change, the more valued schedule was in effect. In contrast, the abrupt removal of the more valued stimulus terminated the only currently effective support for the observing response, and the observing response underwent extinction before the subtle new discrimination could be formed. This conclusion is entirely consistent in spirit with Fantino's (1977) and Dinsmoor's (1983) later interpretations of observing in such instances, discussed earlier.

In the present research, we sought to examine further the relation between Kendall's (1974) fading procedure and the maintenance of observing when only the less valued stimulus was produced. In Experiment 1, we investigated whether the maintenance of observing after fad- ing depended on the receipt of food in the presence of the less valued stimulus. Recall that Kendall's less valued stimulus was still associated with some degree of food reinforcement. Although Kendall favored a discrimination interpretation of his data, he also acknowledged that the less valued stimulus was associated with food reinforcement in his study. He commented that the data from his procedure "might not be comparable to [those from a procedure with] a less valued component in which no reinforcement was delivered"' (p. 214).

Of some interest, therefore, is whether results comparable to those of Kendall (1974) would be obtained if the less valued stimulus was not associated with reinforcement. In Experiment 1, we sought to provide the answer to this question by using the fading procedure with an FR1 observing response schedule, when the more valued stimulus was correlated with an FR35 schedule, but when the less valued stimulus was correlated with 2 min of extinction (EXT 2 min).

If observing when the single response produced a stimulus correlated with extinction was comparable to that when the single response produced a stimulus correlated with the FI 2-min schedule, then further credibility would be added to Kendall's (1974) original discrimination interpretation. (See also Dinsmoor's [1983, p. 719] endorsement of this interpretation.) According to this interpretation, the fading procedure may be regarded as an effective means of facilitating the discrimination that the more valued schedule is in effect if there is no stimulus change after a single response.

On the other hand, if observing was not comparable, a set of provocative implications follows. Presumably, one may conclude that when a less valued stimulus is not associated with food, it is not reinforcing. However, when it is associated with food, it may become reinforcing by virtue of the fading procedure, as in Kendall (1974). Moore $(1983$, p. $711 ; 1985$, p. 99) has indicated that this possibility cannot be ruled out.

Therefore, if observing is not maintained when the lower valued stimulus is correlated with extinction, then presumably the fading procedure may be regarded as an effective means of endowing a less valued stimulus with conditioned reinforcing effectiveness, but only to the extent that the stimulus is associated with food. An interpretation suggesting that the fading procedure facilitated the discrimination that the more valued schedule was in effect would be in error. In any case, results suggesting that the less valued stimulus is reinforcing under any conditions would be especially provocative in light of all the prior research which shows that the less valued stimulus, even when associated with food, is not reinforcing and may even be punishing (Dinsmoor, 1983).

In Experiment 2, we examined the effects of the fading procedure when stimulus changes were produced according to an intermittent schedule, rather than by a single response. Recall that Kendall (1974) hypothesized, and Dinsmoor (1983) agreed, that observing was maintained in his study because the absence of a stimulus 
change after a single peck signified that the more valued component was in effect. The possibility that the less valued stimulus had become reinforcing via the fading procedure cannot technically be ruled out, even though the less valued stimulus was not associated with food reinforcement. An experimental test to determine whether the less valued stimulus should be regarded as reinforcing would have to be predicated on the logic of Dinsmoor et al. (1972, pp. 80-81).

According to this logic, if observing was maintained because the less valued stimulus had genuinely developed conditioned reinforcing properties, independent of its association with reinforcement, then one would expect observing to be similarly maintained when the schedule according to which stimuli were produced was intermittent, rather than FRI.

On the other hand, suppose the fading procedure facilitated the discrimination that the more valued schedule was in effect when a response did not produce a stimulus change. In this case, observing should not be well maintained when the majority of observing responses produce no stimulus change, as when the observing schedule is intermittent, even if a fading procedure is followed.

In Experiment 2, we therefore examined the effects of the fading procedure when stimulus changes were produced according to a variable-interval (VI) schedule. Also, to conduct the strongest test of the reinforcing effectiveness of the less valued stimulus, in Experiment 2 we employed a stimulus that was correlated with a 2 -min interfood interval. The reasoning was that if a less valued stimulus associated with food was not reinforcing, then a less valued stimulus associated with extinction would not be reinforcing either.

\section{EXPERIMENT 1}

In this experiment, we examined the effects of the fading procedure when the observing requirement was a single response, and when the less valued stimulus was correlated first with an FI 2-min schedule, and then with a 2 -min period of extinction (EXT $2 \mathrm{~min}$ ).

\section{Method}

Subjects. The subjects were 3 adult male pigeons (P-22, P-23, and P-24) of mixed breeds and various experimental histories. The pigeons were deprived to $75 \%-80 \%$ of their free-feeding weights. Sessions were conducted 6 days per week under approximately 21-22 $\mathrm{h}$ of food deprivation.

Apparatus. Two standard two-key operant chambers for pigeons were employed. Conventional electromechanical programming equipment, located in a room adjacent to the chambers, controlled events in the chambers and recorded the data

Procedure. The pigeons were first given preliminary training on an FR35 FI 2-min compound schedule, then given observing response training on the FR35 FI 2-min schedule with the fading procedure, and finally given observing response training on an FR35 EXT 2-min compound schedule with the fading procedure.

The reinforcer was $3 \mathrm{sec}$ of access to mixed grain. During grain presentations, a light was illuminated over the elevated hopper and the keylight went off. Sessions throughout the experiment ended after either 40 reinforcers or $2 \mathrm{~h}$.
A percentage reinforcement manipulation was also employed. In this manipulation, reinforcement was presented with a probability of .5 in each component. A percentage reinforcement manipulation was used, rather than reinforcement in each component, in order to increase the number of FR components per session available for the fading procedure without satiating the subject.

Thus, during a typical experimental session, a pigeon was exposed to approximately $40 \mathrm{FR}$ components and $40 \mathrm{FI}$ components. The pigeon would therefore typically receive 20 reinforcements on the FR schedule and 20 reinforcements on the FI schedule. When food reinforcers were not presented, the keylight went off and the hopper light came on, but the hopper was not elevated. This percentage reinforcement manipulation remained in effect throughout the experiment.

During the observing response training, both the right and the left keys were transilluminated with white light. The first response to the right key (the observing key) after a schedule came into effect darkened the key and simultaneously produced either the red or the green light on the left key (the food key), depending upon which schedule, FI or FR, was in effect. Following Kendall's (1974) notation, the red light, the stimulus correlated with the FI schedule (the less valued schedule), is referred to as the SFI, and the green light, the stimulus correlated with the FR schedule (the more valued schedule), is referred to as the SFR. Responses to the left key when it was white, red, or green were reinforced according to the prevailing schedule. Thus, the observing response altered only the stimulus conditions under which food was obtained and not the frequency of obtaining food.

Throughout the experiment, a single response on the observing key was sufficient to change stimuli from white to red or green on the food key (FRl on the observing key). The left key remained red or green and the right key remained dark until the end of the component. Following a food reinforcement, the food key and observing key again became white and remained white until the next observing response. During this phase and throughout the remainder of the experiment, observing was considered stable after three consecutive sessions in which the pigeons responded on the right key in at least $80 \%$ of the components, or if in fewer than $80 \%$ of the components, at a rate that appeared stable by visual inspection.

Fading with FR35 FI 2 min. During the fading procedure, the SFR was produced during only some of the FR components, given an observing response. When the FR component was in effect and a peck did not produce the SFR, the exteroceptive stimuli did not change and further pecks were ineffective. An observing response produced the SFR (or not, as specified by the procedure) during the remaining FR components, as well as the SFI during all FI components.

In the first step of the fading procedure, the SFR was not available in $10 \%$ of the FR components (i.e., SFR availability was $90 \%$ ). Therefore, since there was an average of 40 FR components per session, the observing response would be ineffective during approximately 4 FR components. Following training under these conditions, an observing response was made ineffective in progressively more FR components. The percentages (reflecting the proportion of ratios in which the SFR was available) from the beginning to the end of fading were $90 \%, 80 \%, 70 \%, 60 \%, 50 \%, 30 \%, 10 \%$, and $0 \%$. In the $0 \%$ condition, an observing response was never effective in producing the SFR.

Fading with FR35 EXT 2 min. Following training on the fading procedure with the FR35 FI 2-min compound schedule, the pigeons were trained on a mixed, then multiple, FR35 EXT 2-min compound schedule with randomly alternating components. The percentage reinforcement manipulation regarding grain presentations remained in effect. After preliminary MULT FR35 EXT 2-min training, the pigeons were given an opportunity to convert the MIX FR35 EXT 2-min schedule to the corresponding multiple schedule by means of an observing response, as in the first portion of the experiment. 
As soon as stable observing developed, the fading procedure (Kendall, 1974) was initiated for the FR35 EXT 2-min compound schedule. As described above, the SFR (the more valued stimulus, a green keylight) was gradually faded out as a consequence of observing during a portion of the FR components. A single peck produced the SFR as usual during the remaining FR components, as well as the SEXT (the less valued stimulus, a red keylight) during all EXT components. The percentages (reflecting the probability that the first peck on the observing key during the FR component would produce the SFR) from the beginning to the end of fading were $90 \%, 80 \%, 70 \%, 60 \%, 50 \%, 30 \%, 10 \%$, and $0 \%(\mathrm{P}-23)$, and $90 \%, 70 \%, 50 \%, 30 \%, 10 \%$, and $0 \%$ (P-22 and P-24). Immediately following the $0 \%$ condition of the fading, the SFR was reinstated for P-22 and P-24 for 20 sessions, and then abruptly removed as a consequence of observing in all FR components. For P-23, the SFR was first reinstated for 9 sessions, then abruptly removed, reinstated for 20 sessions, and again abruptly removed.

\section{Results and Discussion}

The results are expressed in terms of the observing ratio, which was used by Kendall and Gibson (1965) and Kendall (1974). The observing ratio is the number of observing responses during a session, divided by the number of schedule components during a session. A ratio of 1.0 is the maximum obtainable ratio, indicating that an observing response occurred during every schedule component in that session. An observing response was scored for only the first peck to the observing key during a component. If additional pecks occurred, they were not scored as observing responses, since the observing response is the one that produces the stimulus. In conditions when a stimulus was unavailable, an observing response was scored if at least one peck was made to the observing key, but additional pecks did not count as additional observing responses.

The top panel of Figure 1 presents the observing ratios for individual pigeons with the FR35 FI 2-min compound schedule. The data points in the figure are averages of the data from the last three sessions at each probability level; they are taken from Table 1 in the Appendix.

As is shown in the top panel of Figure 1, the observing ratios for P-23 and P-24 were not much affected during most of the fading procedure when the less valued schedule was FI 2 min. The observing ratio for P-23 decreased when the SFR was available during only $10 \%$ of the FR components. The observing ratio for P-22 was initially similar to that for P-23 and P-24, but then decreased from 0.95 at $80 \%$ to 0.75 at $50 \%$ availability. However, the observing ratio for P-22 then followed largely the same pattern as those of the other two pigeons and remained within the $0.70-0.80$ range until the SFR $0 \%$ condition. The observing ratios for the other pigeons also decreased when all of the SFRs were unavailable. When the SFR was available on $10 \%$ of the FR components, the lowest observing ratio was 0.74 (P-22 and $P-23)$. When the SFR was unavailable on all the FR components, the highest observing ratio was 0.61 (P-24). Thus, although observing did decrease slightly when the final $10 \%$ of the SFRs were removed, it still continued at an appreciable rate when no SFR was produced.

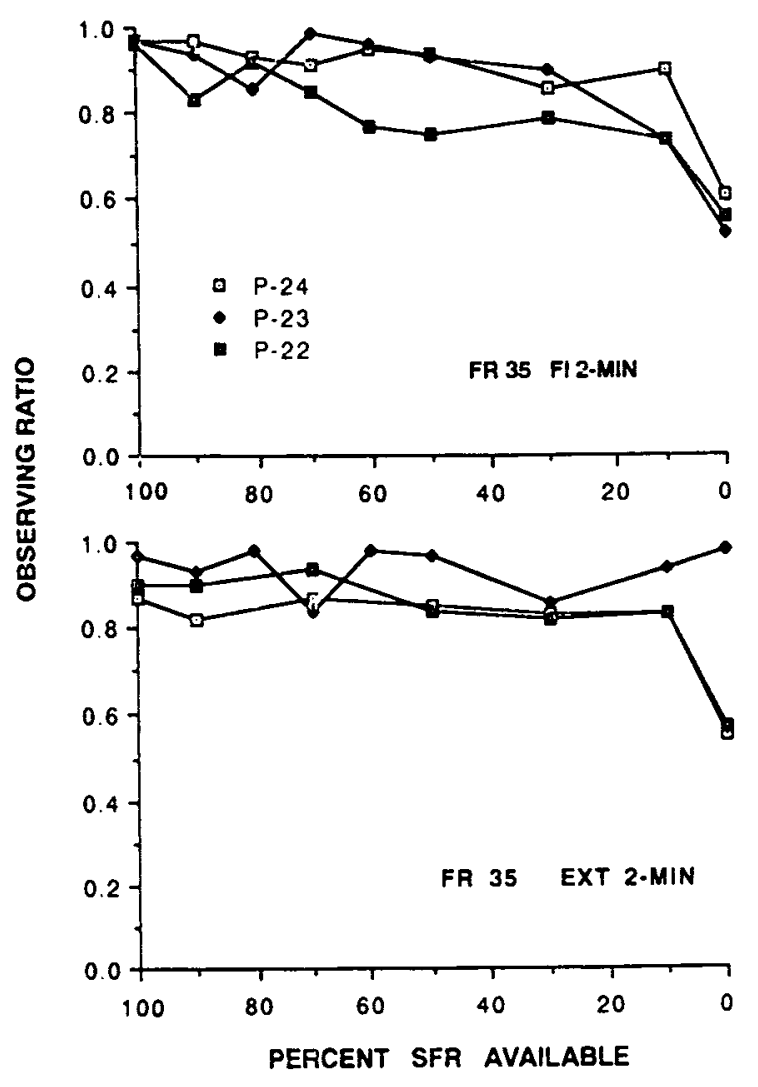

Figure 1. Experiment 1: The top panel shows the effect of fading out the SFR (the fixed-ratio stimulus) with the FR35 FI 2-min compound schedule. The bottom panel shows the effect of fading out the SFR with the FR35 EXT 2-min compound schedule. The observing ratios are plotted for each pigeon for each condition of the fading procedure.

The results of this phase of training indicate that the use of a fading procedure reliably results in the maintenance of observing when the more valued stimulus is not available. The removal of the final $10 \%$ of the SFR, making the SFR unavailable in all FR components but still allowing the production of the SFI in all FI components, resulted in a decline in the observing ratio to the $0.50-0.60$ range. Both of these findings are consistent with Kendall (1974), who found that a similar degree of observing was maintained when the more valued stimulus was not available, using the same procedure.

The bottom panel of Figure 1 presents the observing ratios for individual pigeons with the FR35 EXT 2-min compound schedule. The data points in the figure are averages of the data from the last three sessions at each probability level, and are taken from Table 1 in the Appendix.

As is shown in the bottom panel, the observing ratio for P-23 did not decrease below 0.80 ; the lowest point was 0.84 . The observing ratios of $\mathrm{P}-22$ and $\mathrm{P}-24$ also remained above 0.80 during most of the fading procedure. As in the first procedure, removing the final $10 \%$ of the SFRs resulted in a decrease in observing for these two 
pigeons. The observing ratios decreased to 0.57 for $\mathrm{P}-22$ and 0.55 for $\mathrm{P}-24$. The observing ratio for $\mathrm{P}-23$, however, did not decrease when the final $10 \%$ of the SFR was removed.

Table 1 (see the Appendix) presents additional data from individual pigeons during training with FR35 FI 2 min and FR35 EXT 2 min. The data are expressed as averages from the last three sessions at each probability level. Table 1 gives the average time spent per component in the presence of the SFR and the SFI/SEXT stimuli. Because of the percentage reinforcement procedure, the average IRI associated with the SFR and SFI is actually twice the average time per component. In any case, comparison of the times confirms that the IRI associated with green (the SFR) was shorter than that associated with the red (the SFI/SEXT), and that the green was therefore the more valued stimulus indeed.

As is shown in Table 1, an additional manipulation was performed after the second fading procedure with FR35 EXT 2 min: The SFR was reinstated and then removed abruptly, as in Kendall (1974). Reinstatement of the SFR produced an increase in the observing ratios for all pigeons. Following the abrupt removal of the SFR, the observing ratios for P-22 and P-24 decreased to 0.06 and 0.21 , thereby showing the difference between the faded and abrupt removal of SFR for these 2 subjects. However, the abrupt removal of the SFR had little effect on the observing ratio of P-23. The mean decrease in observing ratio for all 3 subjects was around $50 \%$. These results are similar to those of Kendall (1974) after a comparable manipulation, except for greater individual variability in the present case. That is, after his subjects had been exposed to the fading procedure, Kendall also reinstated the SFR for a time and then abruptly removed it. When the abrupt removal of SFR followed the faded removal, the observing ratios for all 3 of Kendall's subjects decreased from nearly 1.0 to approximately .5 .

In summary, the results of Experiment 1 suggest that observing will be reliably maintained when a fading procedure is followed and when stimulus changes are produced by a single response, even if the less valued stimulus is not associated with food reinforcement. Thus, the maintenance of observing after the fading procedure does not seem to depend critically on the relation between the less valued stimulus and food reinforcement. The observing data for the 3 pigeons show the same pattern of responding after the current fading procedure, regardless of whether the less valued schedule was FI or EXT.

\section{EXPERIMENT 2}

In this experiment, we examined the effects of the fading procedure when the observing schedule was intermittent, and when the less valued stimulus was correlated with a 2-min interfood interval.

\section{Method}

Subjects. Six pigeons served as subjects in Experiment 2. Three (P-22, P-23, P-24) had previously served in Experiment 1. Three new pigeons (P-5, P-8, and P-9), with histories comparable to those described in Experiment 1, were also employed.

Apparatus. The apparatus from Experiment 1 was used.

Procedure. The features of Experiment 2 were generally the same as those of Experiment 1, with the following two exceptions:

First, the schedule according to which an observing response produced a stimulus change was intermittent (i.e., VI), rather than FR1. The use of the VI schedule was the key element of the procedure, of course.

Second, the less valued schedule was FT 2 min (fixed time). Thus, at the conclusion of this component, reinforcement was delivered independently of a response with the probability of .5 . The less valued component was changed to FT in Experiment 2, so that any decreases in observing would not be attributable to a generalization decrement arising from reduced overall reinforcement.

Reinforcement was delivered with a probability of 0.5 at the conclusion of the FR35 schedule as well. When reinforcement was not delivered on either schedule, the food hopper was simply illuminated for $3 \mathrm{sec}$, but not elevated as in Experiment 1 . Sessions terminated after 40 reinforcers or $3 \mathrm{~h}$, whichever came first.

In preliminary training, the pigeons were exposed first to a mixed schedule and then to a multiple schedule, with randomly alternating FR35 and FT 2-min components. Following exposure to MULT FR35 FT 2 min, the pigeons were given an opportunity to convert the MIX FR35 FT 2-min schedule to the corresponding multiple schedule by an observing response. The schedules according to which the observing response produced stimulus changes were VI $15 \mathrm{sec}$ for P-5, P-8, P-9, P-15, P-22, and P-24, and VI $30 \mathrm{sec}$ for $P-23$. (Readers may note that these schedule values are shorter than the VI 60-sec and VI 120-sec schedules used in Dinsmoor et al. [1972]. Shorter VI schedules were employed because we were concerned in the present experiment with detecting decrements in responding, and we desired a relatively rapid rate of responding during baseline conditions.) Thus, the first response on the observing key after the IRI of the VI schedule had elapsed satisfied the observing schedule, and it produced a stimulus change (or not) as specified by the control apparatus. If the FR35 component was in effect, the key color changed from white to green (SFR, the more valued stimulus) with the experimentally specified probability. If the FT 2-min component was in effect, the key color changed from white to red (SFT, the less valued stimulus) every time the schedule was satisfied.

As was described in Experiment 1, the SFR (i.e., green) was then gradually faded out by systematically decreasing the probability of a stimulus change when the VI schedule was satisfied. The SFT was presented each time the observing schedule was satisfied. P-22, $\mathrm{P}-23$, and $\mathrm{P}-24$ were exposed to the fading sequence four times. P-8 was exposed to the fading sequence three times, and P-9 was exposed twice. In the third exposure for P-8, behavior was examined at each probability level for a fixed number of 15 sessions during the fading procedure. P-5 was exposed to the fading sequence once, but more sessions were conducted at the lower probabilities than was the case for any other pigeon.

\section{Results and Discussion}

The principal dependent variable in Experiment 2 was the number of responses per minute on the observing key. This measure is conventionally accepted as appropriate for VI observing schedules (Dinsmoor et al., 1972), rather than the observing ratio used in Experiment 1, which is appropriate for FR1 observing schedules. Figure 2 presents the rate of responding on the observing key for individual pigeons with the FR35 FT 2-min compound schedule. The data points are averages from the last three sessions at each probability level; they are taken from Table 2 in the Appendix. 


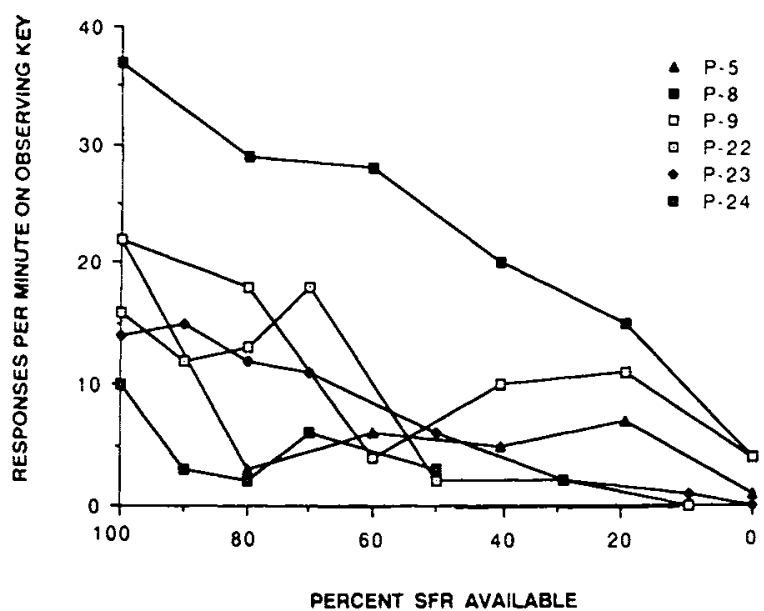

Figure 2. Experiment 2: The effect of fading out the SFR (the fixed-ratio stimulus) with the FR35 FT 2-min schedule is shown. The rate of responding on the observing key is plotted for each pigeon at each probability in the fading procedure.

As is shown in Figure 2, the pigeons responded reliably on the observing key when the probability of producing the SFR was high, and then virtually ceased to respond when the probability of producing the SFR was low. The decrease in responding produced by the decrease in the probability of the SFR is evident for each subject, but it is perhaps most easily seen in the data of P-23. Indeed, P-23's sensitivity to the decreasing probability of the SFR in this experiment may be compared with its performance in later stages of Experiment 2, where unlike that of the other 2 subjects, its performance was not substantially affected by the decrements in the availability of the SFR.

Thus, the data indicate that given a VI observing schedule, the pigeons failed to observe when only the less valued stimulus was produced, even though the fading procedure was followed. These results suggest that the less valued stimulus was not reinforcing. Therefore, the major effect of the fading procedure is indeed to facilitate the discrimination that the more valued schedule is in effect, and not to render reinforcing a less valued stimulus that is associated with food (cf. Moore, 1983, 1985). Importantly, the present interpretation that the less valued stimulus is not reinforcing is based on the same evidence as was that of Dinsmoor et al. (1972), and it confirms and extends the generality of that report.

Two possible concerns are (1) that the results of Experiment 2 might be somehow due to the repeated use of "task-wise" subjects, and (2) that the results are simply transient effects, attributable to insufficient exposure to the experimental conditions. These concerns may be addressed if we consider the data of the three new pigeons (P-5, P-8, and P-9). First, the overall pattern of responding evident in the data for the 3 new pigeons is consistent with that of the pigeons that had served in Experiment 1. Second, P-8 was exposed to the lower probabilities for 15 sessions, and $\mathrm{P}-5$, for somewhat longer (e.g., 23 ses- sions at $40 \%, 20$ sessions at $20 \%$, and 28 sessions at $0 \%$ ). Their behavior was consistent with that of the other pigeons. Therefore, the consistency between the results of the new pigeons and those from Experiment 1 suggests that the results are not a function of previous history or insufficient training.

Table 2 (see the Appendix) presents additional data from individual pigeons in Experiment 2. The data are expressed as averages from the last three sessions at each probability level. Data from the preliminary training are not included. Just as Table 1 in Experiment 1, Table 2 gives the average time spent per component in the presence of the stimuli, the SFR and the SFT. Because of the percentage reinforcement procedure, the average IRI associated with the SFR and SFT is actually twice the average time per component. In any case, comparison of the times confirms that the IRI associated with green (the SFR) was shorter than that associated with the red (the SFT), and that therefore the green was indeed the more valued stimulus.

Table 2 also shows the effect of abrupt removals of the SFR for 2 of the new pigeons that were employed, P-8 and P-9. These abrupt removals tended to produce appreciable decrements in observing for both pigeons, even when the observing schedule was VI $15 \mathrm{sec}$ (cf. Kendall, 1974). These results also support the efficacy of the fading procedure in facilitating the maintenance of observing when the more valued stimulus is not produced.

\section{GENERAL DISCUSSION}

In the present two experiments, pigeons were trained on an observing response procedure in which the probability that a response would produce the more valued of two stimuli was gradually reduced, or faded out, over sessions. Experiment 1 showed that observing was well maintained after a fading procedure when stimulus changes were produced by a single response, regardless of whether the less valued stimulus was associated with food or extinction. Experiment 2 showed that observing was not well maintained after a fading procedure when the stimulus changes were produced according to an intermittent schedule.

Taken together, the results of the two experiments suggest that the absence of an exteroceptive stimulus change after a single observing response may become discriminative in its own right for the more valued component. The fading procedure seems to be an effective means of promoting this very subtle discrimination. However, if observing responses produce a stimulus change according to an intermittent schedule, then the absence of a stimulus change after a response is correlated with both components. Under these conditions, the absence of stimulus change is not discriminative for either component, even though fading is being carried out in one of the components. Consequently, observing is not maintained. When the results are interpreted in this fashion, they are entirely consistent with those reported by Dinsmoor et al. (1972) 
and Kendall (1974), and they are in keeping with the theoretical formulations of observing proposed by Dinsmoor (1983) and in Fantino's (1977) delay reduction account of conditioned reinforcement.

An additional manipulation reported in Kendall (1974) is of some interest. After the more valued stimulus had been removed, Kendall removed the less valued stimulus as well, so that during some sessions neither the more nor the less valued stimulus was produced. The observing ratio of 1 pigeon inexplicably remained at 0.35 , even though pecking produced no stimulus change at all during these sessions. The observing ratios of the other 2 pigeons decreased appreciably. When the less valued stimulus was reinstated, so that observing now produced the less valued but not the more valued stimulus, the observing of all 3 of Kendall's pigeons increased dramatically.

At first blush, the data from Kendall (1974) seem to suggest that the fading procedure had promoted reinforcing properties of the less valued stimulus. Thus, they seem to challenge Dinsmoor's (1983, p. 719) interpretation of Kendall's (1974) work as well as the current research. That is, before fading, observing was not maintained when the less valued stimulus was the only consequence. After fading, observing was maintained. Moreover, when the less valued stimulus was removed after fading, observing decreased, and when the less valued stimulus was reinstated, observing increased.

However, an alternative interpretation is that the resumption of responding when the less valued stimulus was reinstated in Kendall's (1974) work simply represents the reintroduction of the relatively weak reinforcement afforded by the failure of a single response to produce the more valued stimulus. This weak reinforcement is conditional on the availability of the less valued stimulus, of course. Indeed, as has been noted in the present general introduction, Kendall (1974) explicitly considered the possibility that the fading procedure had rendered the less valued stimulus reinforcing, and then explicitly discounted it. Much further research has similarly shown that the less valued stimulus should not be regarded as reinforcing in the same way as the more valued stimulus (see Dinsmoor, 1983, for a review). Thus, with binary outcomes, the failure to produce a stimulus correlated with a given component does seem to indicate that the other component is in effect, and reinforcement may be regarded as dependent upon the more valued component, rather than the information per se about the less valued component.

As Dinsmoor (1983) has noted, cognitive theoretical interpretations of many behavioral processes have recently become fashionable. One currently popular cognitive interpretation of the process called conditioned reinforcement is the information hypothesis. The history of the information hypothesis has been ably reviewed by Dinsmoor (1983), and at least three of the commentators on Dinsmoor's target article endorsed the validity of the hypothesis. The distinctive implication of this hypothesis is that any informative stimulus should serve as a conditioned reinforcer. The operational definition of informativeness is that the stimulus must reduce uncertainty - for example, by being a reliable and valid predictor of food in an otherwise ambiguous context (e.g., Berlyne, 1957).

Translated into an experimental test, the expectation is that the stimulus correlated with the less valued of two schedules should support observing, by virtue of its reliable and valid association with that schedule. However, a review of the literature suggests that observing is not ordinarily well maintained when the less valued of two stimuli is produced by the observing response. The few studies suggesting otherwise are open to alternative interpretation, mostly in line with the findings of the present Experiments 1 and 2 (see Dinsmoor, 1983). For the less valued stimulus to be considered as reinforcing, one would have to argue that the stimulus is simply not a sufficiently strong reinforcer to maintain responding on the intermittent schedule, although it is on the FR1 schedule. The problem is that such an argument then becomes very difficult to test empirically.

Accordingly, the present results join a host of others in suggesting that it would be best to interpret observing in terms of a more traditional analysis, using the language of conditioning processes. The reliability and validity of the associations between exteroceptive stimuli and prevailing schedules emphasized by the information hypothesis are undeniably important factors in observing, but they were not manipulated in the present research (see Kendall, 1973, for a study in which they were). So interpreted, the present results suggest that events reliably correlated with the more valued schedule maintain the observing response. Ordinarily, the events reliably correlated with the more valued schedule are the appearances of the SFR. Hence, the SFR is appropriately designated a conditioned reinforcer. However, given that stimulus changes typically occur after only a single response, the failure to produce a stimulus change may become discriminative in its own right for the presence of the more valued schedule, and thereby maintain the observing response.

\section{REFERENCES}

BERLYNE, D. E. (1957). Uncertainty and conflict: A point of contact between information-theory and behavior-theory concepts. Psychological Review, 64, 329-339.

BraNCH, M. N. (1970). The distribution of observing responses during two VI schedules. Psychonomic Science, 20, 5-6.

Browne, M. P., \& Dinsmoor, J. A. (1974). Wyckoffs observing response: Pigeons leam to observe stimuli for free food but not stimuli for extinction. Learning \& Motivation, 5, 165-173.

DinSMOOR, J. A. (1983). Observing and conditioned reinforcement. Behavioral \& Brain Sciences, 6, 693-728.

Dinsmoor, J. A., Browne, M. P., \& Lawrence, C. E. (1972). A test of the negative discriminative stimuli as a reinforcer of observing. Journal of the Experimental Analysis of Behavior, 18, 79-85.

Dinsmoor, J. A., Flint, G. A., Smith, R. F., \& Viemeister, N. F. (1969). Differential reinforcing effects of stimuli associated with presence or absence of a schedule of punishment. In D. P. Hendry (Ed.), Conditioned reinforcement (pp. 357-384). Homewood, IL: Dorsey Press. 
FANTINo, E. (1977). Conditioned reinforcement: Choice and information. In W. K. Honig \& J. E. R. Staddon (Eds.), Handbook of operant behavior (pp. 313-339). Englewood Cliffs, NJ: Prentice-Hall.

Fantino, E., \& CaSE, D. A. (1983). Human observing: Maintained by stimuli correlated with reinforcement but not extinction. Journal of the Experimental Analysis of Behavior, 40, 193-210.

Jwaideh, A. R., \& Mulvaney, D. E. (1976). Punishment of observing by a stimulus associated with the lower of two reinforcement densities. Learning \& Motivation, 7, 211-222.

KATZ, H. N. (1976). A test of the reinforcing properties of stimuli correlated with nonreinforcement. Journal of the Experimental Analysis of Behavior, 20, 45-56.

KENDALL, S. B. (1973). Effects of two procedures for varying information transmission on observing responses. Journal of the Experimental Analysis of Behavior, 20, 73-83.

KeNDALL, S. B. (1974). Maintenance of observing responses with the less highly valued stimulus in pigeons. Animal Learning \& Behavior, 2, 210-214.

Kendall, S. B., \& GiBson, D. A. (1965). Effects of discriminative stimulus removal on observing behavior. Psychological Record, 15, 545-551.

Killeen, P., Wald, B., \& Cheney, C. D. (1980). Observing behavior and information. Psychological Record, 30, 181-190.

LiEBERMAN, D. A. (1972). Secondary reinforcement and information as determinants of observing behavior in monkeys (Macaca mulatta). Learning \& Motivation, 3, 341-358.
MOORE, J. (1983). Some observations on some observations about some observations. Behavioral \& Brain Sciences, 6, 711.

MOORE, J. (1985). Choice and the conditioned reinforcing strength of informative stimuli. Psychological Record, 35, 89-100.

Mulvaney, D. E., Dinsmoor, J. A., Jwaideh, A. R., \& Hughes, L. H. (1974). Punishment of observing by the negative discriminative stimulus. Journal of the Experimental Analysis of Behavior, 21, 37-44.

Mulvaney, D. E., Hughes, L. H., Jwaddeh, A. R., \& Dinsmoor, J. A. (1981). Differential production of positive and negative stimuli by normal and retarded children. Journal of Experimental Child Psychology, 32, 384-400.

Perone, M., \& Baron, A. (1980). Reinforcement of human observing by a stimulus correlated with extinction or increased effort. Journal of the Experimental Analysis of Behavior, 34, 239-261.

Schaub, R. E. (1969). Response-cue contingency and cue effectiveness. In D. P. Hendry (Ed.), Conditioned reinforcement (pp. 342356). Homewood, IL: Dorsey Press.

SchaUb, R. E., \& HoNiG, W. K. (1967). Reinforcement of behavior with cues correlated with extinction. Psychonomic Science, 7, 15-16.

Schrier, A. M., Thompson, C. R., \& Spector, N. R. (1980). Observing behavior in monkeys (Macaca asetoids): Support for the information hypothesis. Learning \& Motivation, 11, 355-365.

WALD, B. A., \& Dukich, T. D. (1978). Observing behavior: Redundant stimuli and time since information. Animal Leaming \& Behavior, 6, 380-384.

\section{APPENDIX}

Table 1

Data for Each Pigeon in Experiment 1: Fading with FR35 FI 2 min and FR35 EXT 2 min

\begin{tabular}{|c|c|c|c|c|c|c|}
\hline \multirow[b]{2}{*}{ Pigeon } & \multirow[b]{2}{*}{ Schedule } & \multirow{2}{*}{$\begin{array}{c}\text { Scheduled } \\
\text { Probability } \\
\text { of SFR }\end{array}$} & \multirow{2}{*}{$\begin{array}{l}\text { Percent of FR } \\
\text { Components with } \\
\text { Stimulus Change }\end{array}$} & \multicolumn{2}{|c|}{$\begin{array}{l}\text { Average Time } \\
\text { per Component } \\
\text { in Presence of }\end{array}$} & \multirow{2}{*}{$\begin{array}{c}\text { Overall } \\
\text { Observing } \\
\text { Ratio }\end{array}$} \\
\hline & & & & SFR & SFI/SEXT & \\
\hline \multirow{17}{*}{ P-22 } & MIX FR35 FI 2 min & 1.00 & 1.00 & .13 & 2.08 & 0.96 \\
\hline & MIX FR35 FI $2 \mathrm{~min}$ & 0.90 & 0.90 & .09 & 2.06 & 0.83 \\
\hline & MIX FR35 FI $2 \mathrm{~min}$ & 0.70 & 0.82 & .09 & 2.18 & 0.85 \\
\hline & MIX FR35 FI $2 \mathrm{~min}$ & 0.60 & 0.79 & .09 & 2.00 & 0.77 \\
\hline & MIX FR35 FI 2 min & 0.50 & 0.66 & .07 & 1.69 & 0.75 \\
\hline & MIX FR35 FI 2 min & 0.30 & 0.27 & .04 & .80 & 0.79 \\
\hline & MIX FR35 FI $2 \mathrm{~min}$ & 0.10 & 0.10 & .04 & .67 & 0.74 \\
\hline & MIX FR35 FI $2 \mathrm{~min}$ & 0.00 & 0.00 & 0 & 2.52 & 0.56 \\
\hline & MLX FR35 EXT $2 \min$ & 1.00 & 1.00 & .10 & 1.86 & 0.90 \\
\hline & MIX FR35 EXT $2 \min$ & 0.90 & 0.95 & .10 & 1.81 & 0.90 \\
\hline & MIX FR35 EXT $2 \min$ & 0.70 & 0.87 & .08 & 1.91 & 0.94 \\
\hline & MIX FR35 EXT 2 min & 0.50 & 0.45 & .08 & 1.96 & 0.84 \\
\hline & MIX FR35 EXT 2 min & 0.30 & 0.28 & .06 & 1.92 & 0.82 \\
\hline & MIX FR35 EXT $2 \min$ & 0.10 & 0.08 & .06 & 1.11 & 0.83 \\
\hline & MIX FR35 EXT $2 \mathrm{~min}$ & 0.00 & 0.00 & 0 & 1.55 & 0.57 \\
\hline & MIX FR35 EXT $2 \mathrm{~min}$ & 1.00 & 1.00 & .16 & 1.84 & 0.72 \\
\hline & MIX FR35 EXT $2 \mathrm{~min}$ & 0.00 & 0.00 & 0 & 1.45 & 0.06 \\
\hline \multirow[t]{11}{*}{ P-23 } & MIX FR35 FI 2 min & 0.80 & 0.78 & .25 & 2.17 & 0.86 \\
\hline & MIX FR35 FI $2 \mathrm{~min}$ & 0.70 & 0.77 & .22 & 1.87 & 0.99 \\
\hline & MIX FR35 FI $2 \mathrm{~min}$ & 0.60 & 0.63 & .36 & 2.00 & 0.96 \\
\hline & MIX FR35 FI 2 min & 0.50 & 0.55 & .24 & 2.06 & 0.93 \\
\hline & MIX FR35 FI $2 \mathrm{~min}$ & 0.30 & 0.34 & .06 & 1.67 & 0.90 \\
\hline & MIX FR35 FI 2 min & 0.10 & 0.13 & .06 & 1.90 & 0.74 \\
\hline & MIX FR35 FI $2 \mathrm{~min}$ & 0.00 & 0.00 & 0 & .76 & 0.52 \\
\hline & MIX FR35 EXT 2 min & 1.00 & 1.00 & .33 & 1.85 & 0.97 \\
\hline & MIX FR35 EXT 2 min & 0.90 & 0.93 & .35 & 1.88 & 0.93 \\
\hline & MIX FR35 EXT 2 min & 0.80 & 0.76 & .25 & 1.90 & 0.98 \\
\hline & MIX FR35 EXT $2 \mathrm{~min}$ & 0.70 & 0.73 & .32 & * & 0.84 \\
\hline
\end{tabular}


Table 1 (Continued)

\begin{tabular}{|c|c|c|c|c|c|c|}
\hline \multirow[b]{2}{*}{ Pigeon } & \multirow[b]{2}{*}{ Schedule } & \multirow{2}{*}{$\begin{array}{l}\text { Scheduled } \\
\text { Probability } \\
\text { of SFR }\end{array}$} & \multirow{2}{*}{$\begin{array}{l}\text { Percent of FR } \\
\text { Components with } \\
\text { Stimulus Change }\end{array}$} & \multicolumn{2}{|c|}{$\begin{array}{l}\text { Average Time } \\
\text { per Component } \\
\text { in Presence of }\end{array}$} & \multirow{2}{*}{$\begin{array}{c}\text { Overall } \\
\text { Observing } \\
\text { Ratio } \\
\end{array}$} \\
\hline & & & & SFR & SFI/SEXT & \\
\hline & MIX FR35 EXT 2 min & 0.60 & 0.67 & .29 & 1.90 & 0.98 \\
\hline & MIX FR35 EXT 2 min & 0.50 & 0.63 & .20 & 1.82 & 0.97 \\
\hline & MIX FR35 EXT 2 min & 0.30 & 0.35 & .11 & $*$ & 0.86 \\
\hline & MIX FR35 EXT 2 min & 0.10 & 0.11 & .53 & 1.94 & 0.94 \\
\hline & MIX FR35 EXT $2 \mathrm{~min}$ & 0.00 & 0.00 & 0 & 1.93 & 0.98 \\
\hline & MIX FR35 EXT 2 min & 1.00 & 1.00 & .25 & 1.96 & 1.00 \\
\hline & MIX FR35 EXT $2 \mathrm{~min}$ & 0.00 & 0.00 & 0 & * & 0.98 \\
\hline & MIX FR35 EXT $2 \mathrm{~min}$ & 1.00 & 0.00 & .25 & 1.93 & 0.97 \\
\hline & MIX FR35 EXT $2 \mathrm{~min}$ & 0.00 & 0.00 & 0 & 1.95 & 0.98 \\
\hline \multirow[t]{18}{*}{ P-24 } & MIX FR35 FI 2 min & 1.00 & 1.00 & .39 & * & 0.97 \\
\hline & MIX FR35 FI 2 min & 0.90 & 0.98 & .33 & 1.86 & 0.97 \\
\hline & MIX FR35 FI 2 min & 0.80 & 0.79 & .05 & 1.94 & 0.93 \\
\hline & MIX FR35 FI 2 min & 0.70 & 0.71 & .05 & 1.58 & 0.91 \\
\hline & MIX FR35 FI 2 min & 0.60 & 0.64 & .16 & $*$ & 0.95 \\
\hline & MIX FR35 FI 2 min & 0.50 & 0.54 & .17 & 1.67 & 0.94 \\
\hline & MIX FR35 FI 2 min & 0.30 & 0.36 & .11 & 1.83 & 0.86 \\
\hline & MIX FR35 FI $2 \mathrm{~min}$ & 0.10 & 0.12 & .05 & 1.51 & 0.90 \\
\hline & MIX FR35 FI 2 min & 0.00 & 0.00 & 0 & 1.24 & 0.61 \\
\hline & MIX FR35 EXT 2 min & 1.00 & 1.00 & .67 & 1.83 & 0.87 \\
\hline & MIX FR35 EXT 2 min & 0.90 & 0.92 & .33 & 1.93 & 0.82 \\
\hline & MIX FR35 EXT $2 \mathrm{~min}$ & 0.70 & 0.71 & .16 & 1.72 & 0.87 \\
\hline & MIX FR35 EXT 2 min & 0.50 & 0.50 & .12 & 1.78 & 0.85 \\
\hline & MIX FR35 EXT $2 \mathrm{~min}$ & 0.30 & 0.30 & .11 & 1.65 & 0.83 \\
\hline & MIX FR35 EXT 2 min & 0.10 & 0.10 & .06 & 1.61 & 0.83 \\
\hline & MIX FR35 EXT $2 \mathrm{~min}$ & 0.00 & 0.00 & 0 & 1.75 & 0.55 \\
\hline & MIX FR35 EXT $2 \mathrm{~min}$ & 1.00 & 1.00 & .37 & 1.52 & 0.67 \\
\hline & MIX FR35 EXT $2 \mathrm{~min}$ & 0.00 & 0.00 & $\mathbf{0}$ & 1.64 & 0.24 \\
\hline
\end{tabular}

Note-Included for each pigeon are the schedule; the scheduled probability of producing SFR; the obtained percent of FR components with a stimulus change; the average time per component in the presence of SFR and SFI/SFT (in minutes); and the overall observing ratio, calculated as the proportion of all components with an observing response. * Data not available for that condition.

Table 2

Data for Each Pigeon in Each Condition of Experiment 2: Fading with FR35 FT 2 min

\begin{tabular}{|c|c|c|c|c|c|c|c|c|c|c|}
\hline \multirow[b]{2}{*}{ Pigeon } & \multirow[b]{2}{*}{ Schedule } & \multirow{2}{*}{$\begin{array}{l}\text { Scheduled } \\
\text { Probability } \\
\text { of SFR }\end{array}$} & \multicolumn{3}{|c|}{$\begin{array}{l}\text { Obtained Percent } \\
\text { of Components with } \\
\text { Stimulus Change }\end{array}$} & \multicolumn{2}{|c|}{$\begin{array}{l}\text { Average Time } \\
\text { per Component } \\
\text { in Presence of }\end{array}$} & \multicolumn{3}{|c|}{$\begin{array}{l}\text { Responses per Minute } \\
\text { on Observing Key }\end{array}$} \\
\hline & & & FR & FT & Overall & SFR & SFT & FR & FT & $\mathrm{FR}+\mathrm{FT}$ \\
\hline \multirow[t]{17}{*}{ P-22 } & MIX FR35 FT $2 \mathrm{~min}$ & 1.00 & 58 & 92 & 75 & .13 & 1.76 & 29 & 19 & 23 \\
\hline & MIX FR35 FT 2 min & 0.90 & 12 & 76 & 40 & .20 & 1.39 & 2 & 2 & 2 \\
\hline & MIX FR35 FT $2 \mathrm{~min}$ & 0.70 & 51 & 93 & 71 & .11 & 1.66 & 20 & 14 & 17 \\
\hline & MIX FR35 FT $2 \mathrm{~min}$ & 0.50 & 6 & 20 & 12 & 0 & 1.85 & 2 & 2 & 2 \\
\hline & MIX FR35 FT $2 \mathrm{~min}$ & 1.00 & 54 & 65 & 59 & .14 & 1.74 & 8 & 4 & 5 \\
\hline & MIX FR35 FT 2 min & 0.90 & 78 & 88 & 83 & .16 & 1.74 & 17 & 11 & 14 \\
\hline & MIX FR35 FT 2 min & 0.70 & 69 & 72 & 71 & .15 & 1.80 & 33 & 13 & 19 \\
\hline & MIX FR35 FT 2 min & 0.50 & 11 & 34 & 23 & .25 & 1.82 & 2 & 1 & 1 \\
\hline & MIX FR35 FT 2 min & 0.30 & 4 & 37 & 20 & 0 & 1.31 & 2 & 1 & 1 \\
\hline & MIX FR35 FT $2 \mathrm{~min}$ & 1.00 & 79 & 93 & 86 & .13 & 1.76 & 20 & 16 & 17 \\
\hline & MIX FR35 FT 2 min & 0.90 & 63 & 88 & 76 & .13 & 1.92 & 26 & 13 & 17 \\
\hline & MIX FR35 FT 2 min & 0.80 & 59 & 93 & 76 & .12 & 1.68 & 18 & 9 & 12 \\
\hline & MIX FR35 FT 2 min & 0.70 & 62 & 100 & 79 & .12 & 1.69 & 14 & 16 & 15 \\
\hline & MIX FR35 FT 2 min & 0.50 & 20 & 65 & 42 & .13 & 1.54 & 5 & 3 & 3 \\
\hline & MIX FR35 FT 2 min & 0.30 & 1 & 60 & 31 & 0 & 1.54 & 4 & 2 & 3 \\
\hline & MIX FR35 FT $2 \mathrm{~min}$ & 0.10 & 0 & 26 & 12 & 0 & 1.28 & $*$ & 0 & $*$ \\
\hline & MIX FR35 FT 2 min & 1.00 & 80 & 98 & 88 & .12 & 1.71 & 13 & 17 & 15 \\
\hline
\end{tabular}

Observing Schedule: VI $15 \mathrm{sec}$ 
Table 2 (Continued)

\begin{tabular}{|c|c|c|c|c|c|c|c|c|c|c|}
\hline \multirow[b]{2}{*}{ Pigeon } & \multirow[b]{2}{*}{ Schedule } & \multirow{2}{*}{$\begin{array}{l}\text { Scheduled } \\
\text { Probability } \\
\text { of SFR } \\
\end{array}$} & \multicolumn{3}{|c|}{$\begin{array}{c}\text { Obtained Percent } \\
\text { of Components with } \\
\text { Stimulus Change }\end{array}$} & \multicolumn{2}{|c|}{$\begin{array}{l}\text { Average Time } \\
\text { per Component } \\
\text { in Presence of }\end{array}$} & \multicolumn{3}{|c|}{$\begin{array}{c}\text { Responses per Minute } \\
\text { on Observing Key }\end{array}$} \\
\hline & & & FR & FT & Overall & SFR & SFT & FR & FT & $\mathrm{FR}+\mathrm{FT}$ \\
\hline \multirow[t]{20}{*}{ P-23 } & MIX FR35 FT 2 min & 1.00 & 60 & 67 & 63 & .23 & $\dagger$ & 29 & 15 & 20 \\
\hline & MIX FR35 FT 2 min & 0.90 & 58 & 65 & 62 & .22 & $\dagger$ & 26 & 14 & 18 \\
\hline & MIX FR35 FT $2 \mathrm{~min}$ & 0.70 & 17 & 19 & 18 & .33 & 1.37 & 5 & 2 & 3 \\
\hline & MIX FR35 FT 2 min & 0.50 & 10 & 49 & 31 & .33 & .72 & 5 & 2 & 2 \\
\hline & MIX FR35 FT $2 \mathrm{~min}$ & 0.30 & 0 & 18 & 9 & 0 & 1.11 & 3 & 1 & 1 \\
\hline & MIX FR35 FT $2 \mathrm{~min}$ & 1.00 & 70 & 75 & 73 & .21 & 1.36 & 25 & 10 & 14 \\
\hline & MIX FR35 FT 2 min & 0.90 & 61 & 86 & 73 & .22 & 1.45 & 17 & 9 & 12 \\
\hline & MIX FR35 FT 2 min & 0.70 & 62 & 91 & 76 & .22 & 1.52 & 16 & 11 & 13 \\
\hline & MIX FR35 FT 2 min & 0.50 & 15 & 95 & 53 & .17 & 1.52 & 11 & 9 & 10 \\
\hline & MIX FR35 FT $2 \mathrm{~min}$ & 0.30 & 4 & 71 & 38 & 1.37 & 1.26 & 3 & 2 & 2 \\
\hline & MIX FR35 FT $2 \mathrm{~min}$ & 1.00 & 45 & 88 & 69 & .18 & 1.51 & 11 & 8 & 9 \\
\hline & MIX FR35 FT 2 min & 0.90 & 28 & 90 & 57 & .19 & 1.56 & 17 & 12 & 14 \\
\hline & MIX FR35 FT 2 min & 0.80 & 22 & 93 & 60 & .15 & 1.33 & 11 & 12 & 12 \\
\hline & MIX FR35 FT $2 \mathrm{~min}$ & 0.70 & 54 & 92 & 74 & .20 & 1.44 & 15 & 15 & 15 \\
\hline & MIX FR35 FT $2 \mathrm{~min}$ & 0.50 & 23 & 81 & 53 & .22 & 1.32 & 8 & 5 & 6 \\
\hline & MIX FR35 FT $2 \mathrm{~min}$ & 0.30 & 3 & 87 & 41 & 0 & 1.25 & 3 & 2 & 2 \\
\hline & MIX FR35 FT 2 min & 0.10 & 0 & 21 & 11 & 0 & 1.08 & 2 & $*$ & 1 \\
\hline & MIX FR35 FT $2 \mathrm{~min}$ & 0.00 & 0 & 20 & 9 & 0 & 1.19 & 1 & $*$ & $*$ \\
\hline & MIX FR35 FT 2 min & 1.00 & 28 & 97 & 65 & .10 & 1.50 & 13 & 14 & 13 \\
\hline & \multicolumn{10}{|c|}{ Observing Schedule: VI $30 \mathrm{sec}$} \\
\hline \multirow[t]{12}{*}{ P-24 } & MIX FR35 FT $2 \mathrm{~min}$ & 1.00 & 87 & 88 & 88 & .30 & 1.65 & 8 & 11 & 9 \\
\hline & MIX FR35 FT $2 \mathrm{~min}$ & 0.90 & 78 & 84 & 81 & .33 & 1.62 & 3 & 5 & 4 \\
\hline & MIX FR35 FT 2 min & 0.70 & 57 & 81 & 68 & .28 & 1.70 & 9 & 10 & 9 \\
\hline & MIX FR35 FT $2 \mathrm{~min}$ & 1.00 & 100 & 97 & 99 & .50 & 1.82 & 1 & 10 & 1 \\
\hline & MIX FR35 FT $2 \mathrm{~min}$ & 0.90 & 95 & 96 & 96 & .35 & 1.53 & 3 & 9 & 5 \\
\hline & MIX FR35 FT 2 min & 0.70 & 72 & 77 & 75 & .42 & 1.61 & 2 & 6 & 4 \\
\hline & MIX FR35 FT 2 min & 0.50 & 38 & 69 & 53 & .33 & 1.63 & 2 & 3 & 2 \\
\hline & MIX FR35 FT $2 \mathrm{~min}$ & 1.00 & 99 & 94 & 96 & .42 & 1.64 & 10 & 14 & 12 \\
\hline & MIX FR35 FT $2 \mathrm{~min}$ & 0.90 & 80 & 72 & 76 & .68 & 1.43 & 1 & 2 & 1 \\
\hline & MIX FR35 FT $2 \mathrm{~min}$ & 0.80 & 83 & 72 & 78 & .78 & 1.46 & 1 & 4 & 1 \\
\hline & MIX FR35 FT $2 \mathrm{~min}$ & 1.00 & 96 & 90 & 93 & .33 & 1.64 & 10 & 13 & 11 \\
\hline & \multicolumn{10}{|c|}{ Observing Schedule: VI $15 \mathrm{sec}$} \\
\hline \multirow[t]{7}{*}{ P-5 } & MIX FR35 FT $2 \mathrm{~min}$ & 1.00 & 39 & 48 & 44 & 1.00 & $\dagger$ & 10 & 22 & 22 \\
\hline & MLX FR35 FT $2 \mathrm{~min}$ & 0.80 & 65 & 76 & 71 & .88 & 1.52 & 3 & 3 & 3 \\
\hline & MIX FR35 FT $2 \mathrm{~min}$ & 0.60 & 44 & 79 & 61 & .44 & 1.00 & 8 & 5 & 6 \\
\hline & MIX FR35 FT $2 \mathrm{~min}$ & 0.40 & 19 & 76 & 47 & .42 & 1.60 & 7 & 4 & 5 \\
\hline & MIX FR35 FT $2 \mathrm{~min}$ & 0.20 & 13 & 97 & 53 & .41 & 1.91 & 7 & 7 & 7 \\
\hline & MLX FR35 FT 2 min & 0.00 & 0 & 56 & 29 & 0 & 1.40 & 1 & 1 & 1 \\
\hline & \multicolumn{10}{|c|}{ Observing Schedule: VI $15 \mathrm{sec}$} \\
\hline \multirow[t]{17}{*}{ P-8 } & MIX FR35 FT 2 min & 1.00 & 69 & 93 & 81 & .10 & 1.75 & 60 & 37 & 47 \\
\hline & MIX FR35 FT 2 inin & 0.00 & 0 & 80 & 35 & 0 & 1.63 & 5 & 4 & 4 \\
\hline & MIX FR35 FT 2 min & 1.00 & 88 & 95 & 92 & .13 & 1.67 & 32 & 25 & 28 \\
\hline & MIX FR35 FT $2 \mathrm{~min}$ & 0.80 & 55 & 96 & 76 & .15 & 1.68 & 31 & 24 & 26 \\
\hline & MIX FR35 FT $2 \mathrm{~min}$ & 0.60 & 27 & 93 & 59 & .09 & 1.64 & 33 & 16 & 22 \\
\hline & MIX FR35 FT 2 min & 0.40 & 25 & 89 & 55 & .40 & 1.47 & 24 & 8 & 13 \\
\hline & MIX FR35 FT 2 min & 0.20 & 10 & 79 & 50 & .35 & 1.60 & 21 & 12 & 14 \\
\hline & MIX FR35 FT $2 \mathrm{~min}$ & 0.00 & 0 & 90 & 48 & 0 & 1.50 & 5 & 4 & 4 \\
\hline & MIX FR35 FT 2 min & 1.00 & 45 & 40 & 74 & .14 & $\dagger$ & 44 & 38 & 40 \\
\hline & MIX FR35 FT $2 \mathrm{~min}$ & 0.80 & 33 & 95 & 64 & .14 & 1.53 & 36 & 22 & 26 \\
\hline & MIX FR35 FT 2 min & 0.60 & 32 & 89 & 61 & .09 & 1.67 & 45 & 25 & 32 \\
\hline & MIX FR35 FT 2 min & 0.40 & 28 & 96 & 67 & .10 & 1.62 & 26 & 17 & 19 \\
\hline & MIX FR35 FT $2 \mathrm{~min}$ & 0.20 & 9 & 91 & 50 & .33 & 1.59 & 26 & 13 & 16 \\
\hline & MIX FR35 FT $2 \mathrm{~min}$ & 0.00 & 0 & 86 & 43 & 0 & 1.47 & 3 & 4 & 3 \\
\hline & MIX FR35 FT $2 \mathrm{~min}$ & 1.00 & 70 & 88 & 78 & .10 & 1.45 & 53 & 35 & 43 \\
\hline & MIX FR35 FT $2 \mathrm{~min}$ & 0.80 & 56 & 94 & 76 & .11 & 1.69 & 60 & 28 & 37 \\
\hline & MIX FR35 FT $2 \mathrm{~min}$ & 0.60 & 39 & 100 & 70 & .14 & 1.58 & 40 & 26 & 31 \\
\hline
\end{tabular}


Table 2 (Continued)

\begin{tabular}{|c|c|c|c|c|c|c|c|c|c|c|}
\hline \multirow[b]{2}{*}{ Pigeon } & \multirow[b]{2}{*}{ Schedule } & \multirow{2}{*}{$\begin{array}{c}\text { Scheduled } \\
\text { Probability } \\
\text { of SFR }\end{array}$} & \multicolumn{3}{|c|}{$\begin{array}{l}\text { Obtained Percent } \\
\text { of Components with } \\
\text { Stimulus Change }\end{array}$} & \multicolumn{2}{|c|}{$\begin{array}{l}\text { Average Time } \\
\text { per Component } \\
\text { in Presence of }\end{array}$} & \multicolumn{3}{|c|}{$\begin{array}{l}\text { Responses per Minute } \\
\text { on Observing Key }\end{array}$} \\
\hline & & & FR & FT & Overall & SFR & SFT & FR & FT & $F R+F T$ \\
\hline & MIX FR35 FT 2 min & 0.40 & 30 & 99 & 65 & .17 & 1.57 & 19 & 17 & 18 \\
\hline & MIX FR35 FT $2 \min$ & 0.20 & 15 & 100 & 59 & .20 & 1.66 & 19 & 20 & 20 \\
\hline & MIX FR35 FT 2 min & 0.00 & 0 & 87 & 44 & 0 & 1.48 & 4 & 3 & 3 \\
\hline & MIX FR35 FT 2 min & 1.00 & 63 & 93 & 78 & .12 & 1.62 & 31 & 20 & 24 \\
\hline & MIX FR35 FT 2 min & 0.00 & 0 & 89 & 44 & 0 & 1.31 & 4 & 2 & 3 \\
\hline & Observing Schedule: & I $15 \mathrm{sec}$ & & & & & & & & \\
\hline \multirow[t]{15}{*}{ P-9 } & MIX FR35 FT 2 min & 1.00 & 83 & 89 & 86 & .17 & 1.79 & 18 & 18 & 18 \\
\hline & MIX FR35 FT 2 min & 0.00 & 0 & 32 & 16 & 0 & $\dagger$ & 5 & 6 & 5 \\
\hline & MIX FR35 FT $2 \min$ & 1.00 & 32 & 100 & 70 & .20 & 1.55 & 29 & 19 & 22 \\
\hline & MIX FR35 FT 2 min & 0.80 & 11 & 98 & 46 & .20 & 1.72 & 15 & 21 & 19 \\
\hline & MIX FR35 FT $2 \mathrm{~min}$ & 0.60 & 14 & 90 & 54 & .20 & 1.47 & 6 & 6 & 6 \\
\hline & MIX FR35 FT $2 \mathrm{~min}$ & 0.40 & 10 & 100 & 52 & .25 & 1.50 & 5 & 9 & 7 \\
\hline & MIX FR35 FT $2 \mathrm{~min}$ & 0.20 & 0 & 91 & 45 & 0 & 1.65 & 9 & 6 & 7 \\
\hline & MIX FR35 FT 2 min & 0.00 & 0 & 94 & 47 & 0 & 1.47 & 3 & 7 & 6 \\
\hline & MIX FR35 FT 2 min & 1.00 & 34 & 87 & 62 & .28 & 1.66 & 44 & 19 & 25 \\
\hline & MIX FR35 FT 2 min & 0.80 & 17 & 94 & 53 & .15 & 1.58 & 25 & 15 & 18 \\
\hline & MIX FR35 FT 2 min & 0.60 & 10 & 52 & 32 & .35 & 1.40 & 4 & 2 & 2 \\
\hline & MIX FR35 FT 2 min & 0.40 & 8 & 92 & 50 & .34 & 1.50 & 11 & 12 & 12 \\
\hline & MIX FR35 FT 2 min & 0.20 & 11 & 98 & 55 & .24 & 1.56 & 15 & 15 & 15 \\
\hline & MIX FR35 FT $2 \mathrm{~min}$ & 0.00 & 0 & 87 & 48 & 0 & 1.32 & 1 & 2 & 2 \\
\hline & \multicolumn{10}{|c|}{ Observing Schedule: VI $15 \mathrm{sec}$} \\
\hline
\end{tabular}

Note-Included are the scheduled probability of producing SFR; the obtained percent of components with a stimulus change; the average time per component (in minutes) spent in the presence of SFR and SFT; and the responses per minute on the observing key in each component. Data from the FR +FT column refer to the average rate of responding on the observing key during the two components. The rate of responding on the observing key was calculated without including responses made or time accumulated when the observing schedule had been satisfied during the FR component and when there was no stimulus change from the MIX stimulus to SFR. The observing schedule for P-5, P-8, P-9, P-22, and P-24 was VI $15 \mathrm{sec}$, and for P-23, VI $30 \mathrm{sec}$. *Indicates rates of responding of less than one per minute. $\quad$ Indicates data not available for that condition. 